\title{
FACTORS OF THE MANIFESTATION OF PROFESSIONAL BURNOUT AND EFFICIENCY OF TEACHERS IN ONLINE LEARNING
}

\author{
Mirzoyan V. Kh, Mikaelyan M.Yu. (Vanadzor State University, \\ Vanadzor, Armenia) \\ mirzoyan900@gmail.com,madmikayelyan@yandex.com

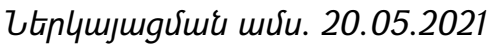

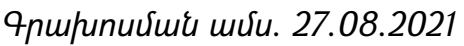

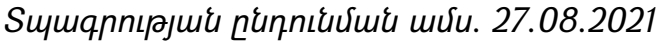

\begin{abstract}
Professional activity plays a huge role and significance in a person's life. It contributes to the knowledge enrichment, skill development, and provides personal and professional growth. At the same time, professional activity can harm a person's physical and mental health and cause professional burnout. Employees in the education system, particularly teachers, have encountered a number of psychological problems as a result of transition to distance learning in connection with COVID-19. Onlinelearning became a catalyst that has accelerated the onset and progression of psychophysical symptoms. The lack of direct interpersonal communication, the emotional connection, the existence of various technical problems, a low level of computer competence, inability to use online tools, isolation and constant fear led to body exhaustion and decreased performance. This was especially noticeable among the teachers working in urban schools.

The article discusses the causes of professional burnout and its manifestations. Professional burnout is harmful not only to a particular person, but also to society as a whole. The article presents psychological factors that affect working capacity, as well as the relationship between professional working capacity and professional burnout. A study was conducted with 280 teachers from urban and rural schools, which resulted in a decrease in working capacity and the existence of professional burnout, and it was revealed that the indicators in two methods are almost double for urban school teachers.
\end{abstract}

Keywords: professional burnout, performance, professional performance, online training.

DOI: https://doi.org/10.46991/SBMP/2022.5.1.083

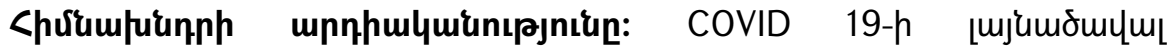

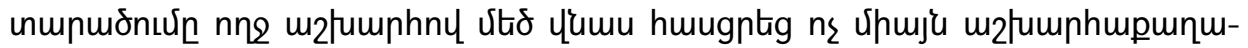

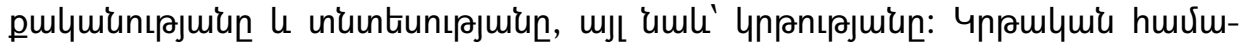




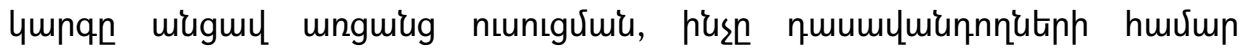

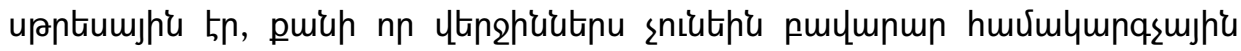

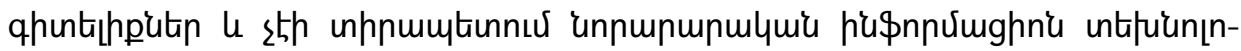

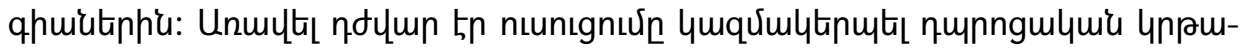

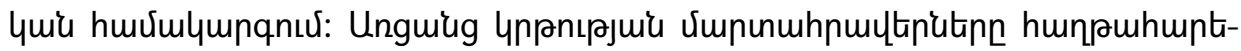

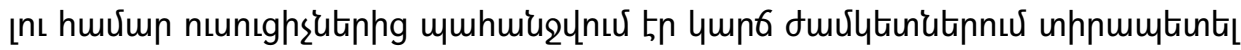

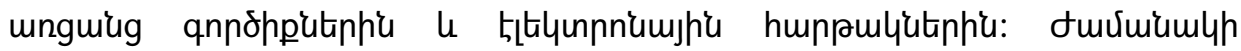

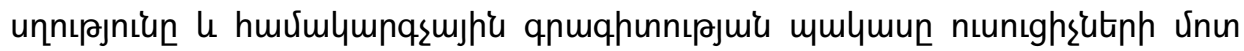

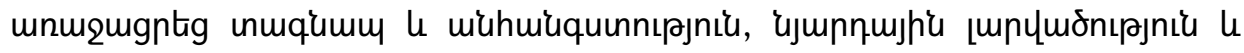

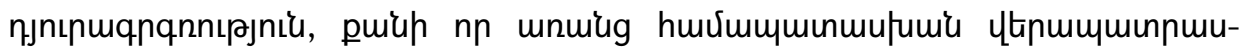

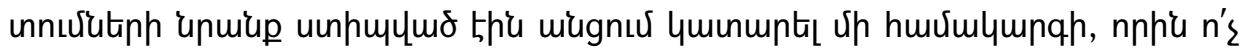

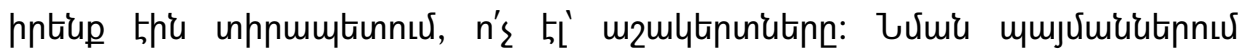

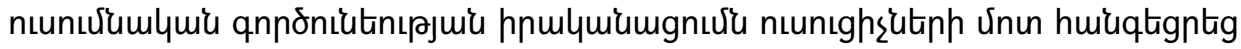

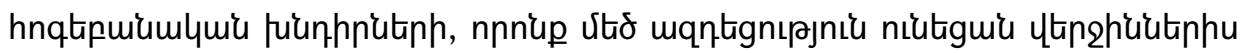

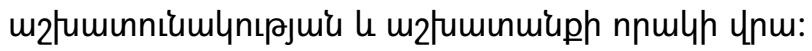

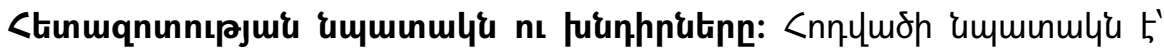

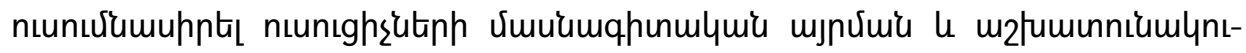

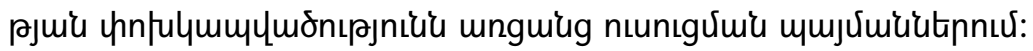

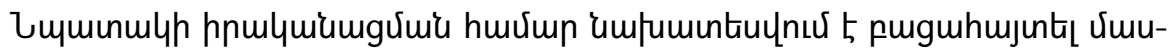

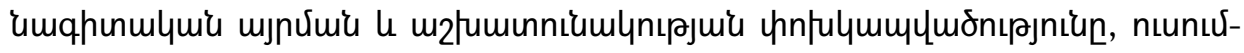

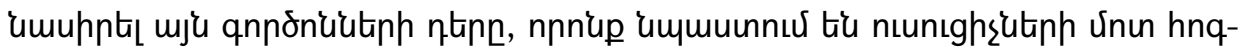

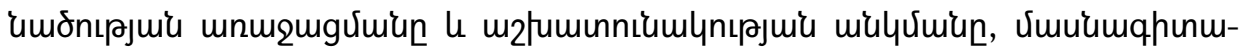

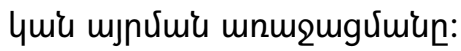

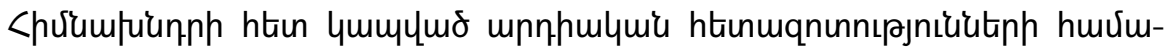

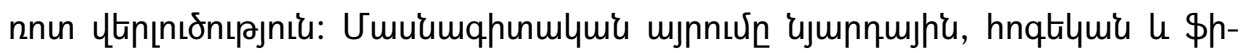

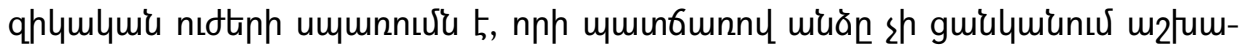

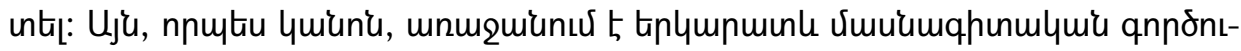

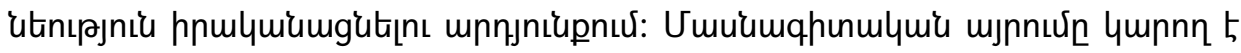

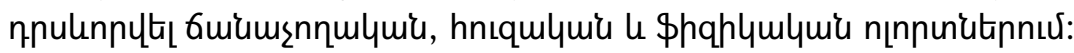

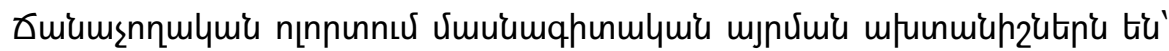

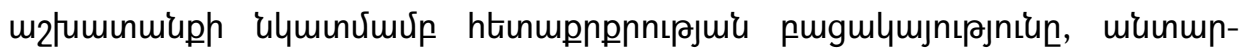

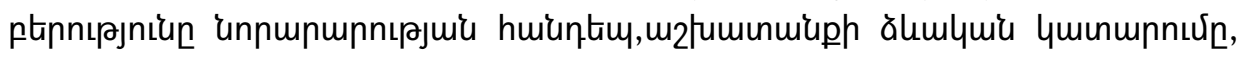

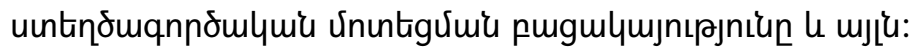

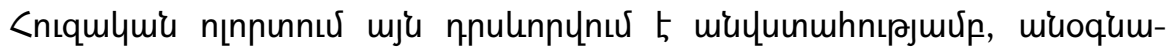

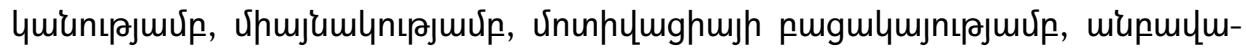

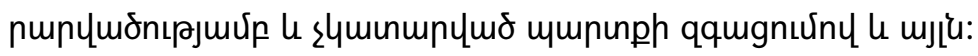

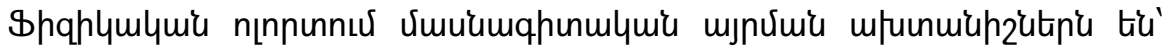

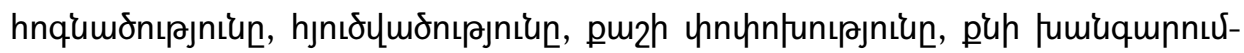

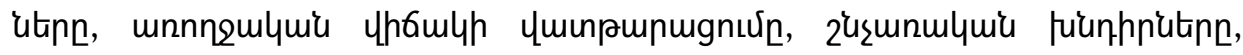




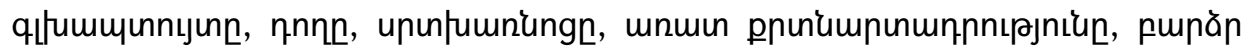

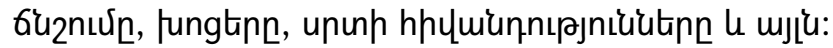

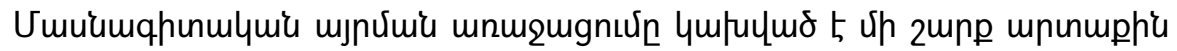

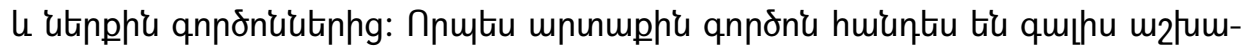

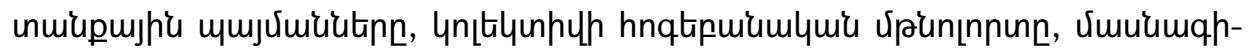

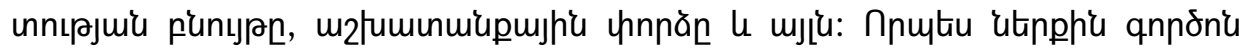

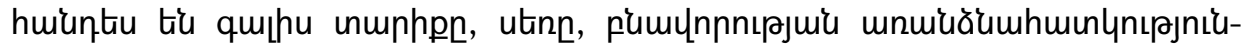

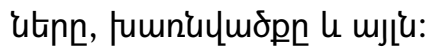

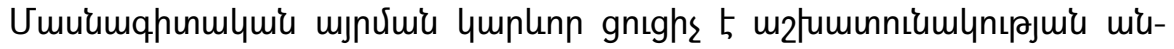

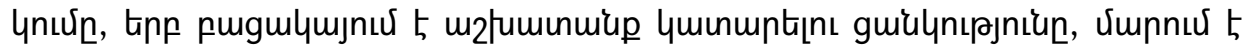

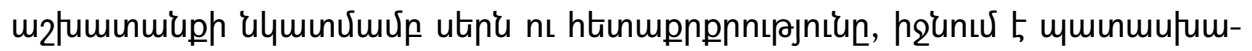

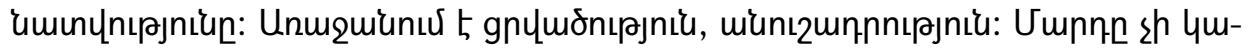

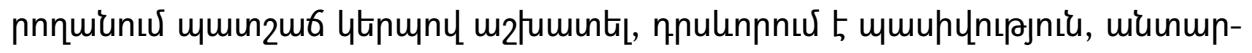

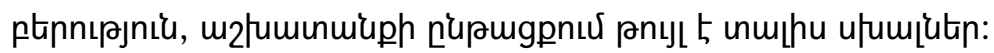

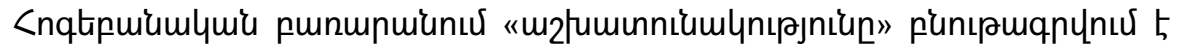

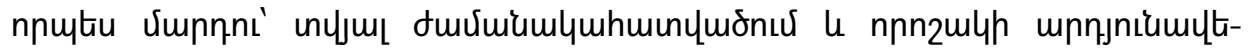

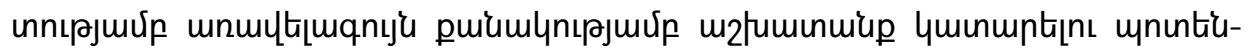
ghwi nünııumlynıpjniu [1]:

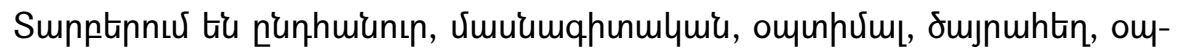

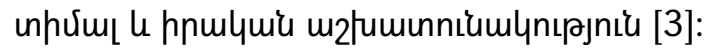

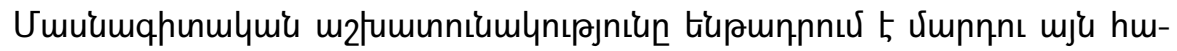

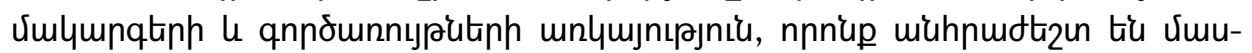

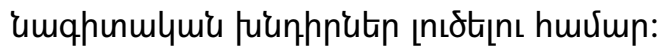

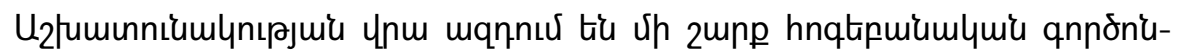

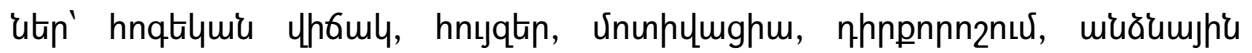

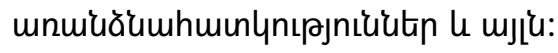

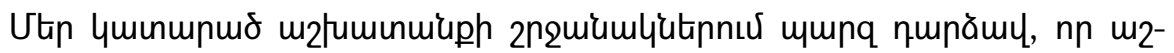

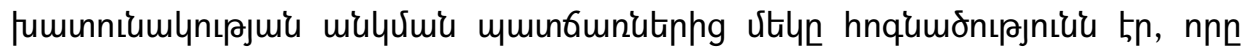

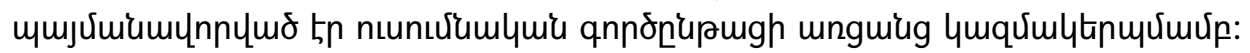

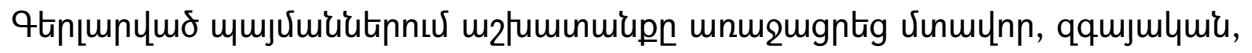

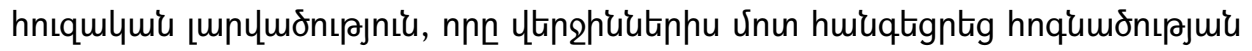

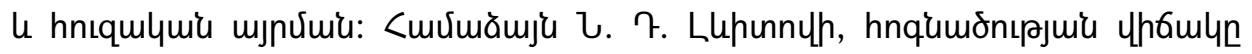

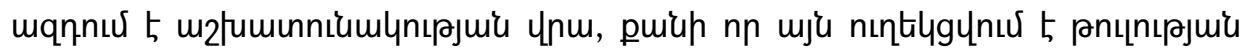

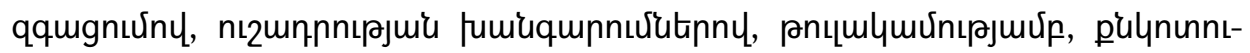

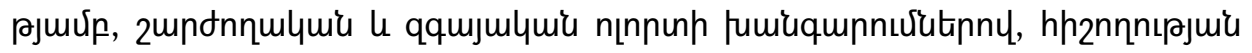

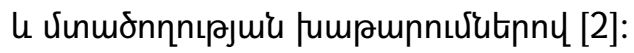

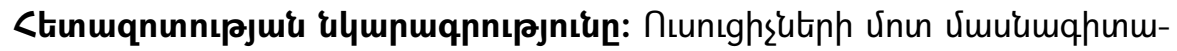

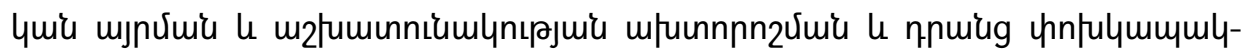

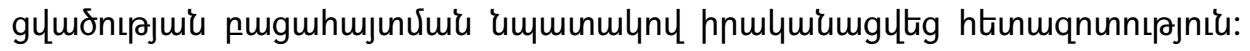

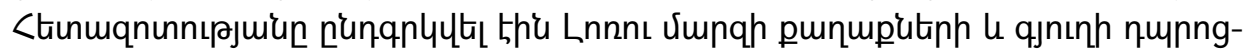




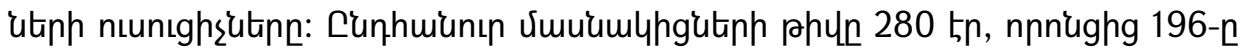

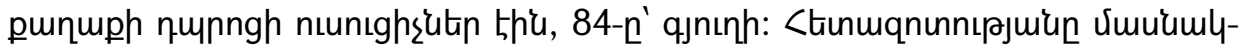

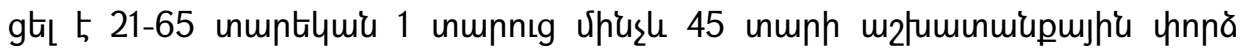

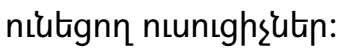

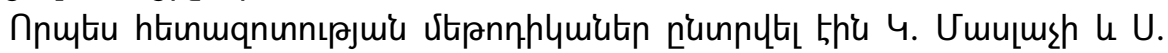

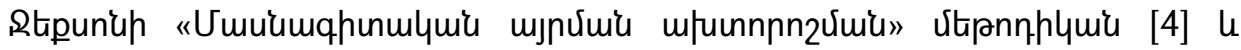

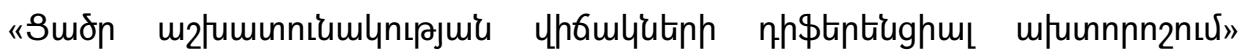
(ДОРС) Utipnnhluititinn [5]:

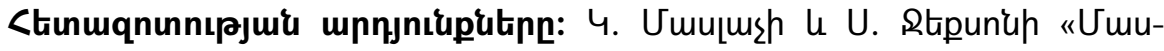

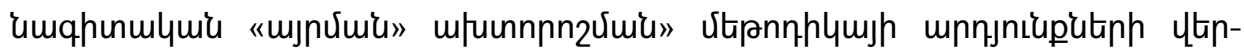

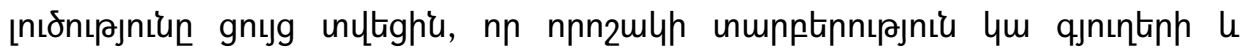

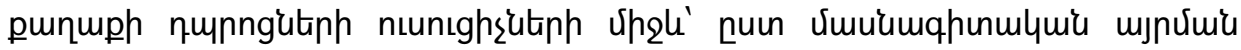

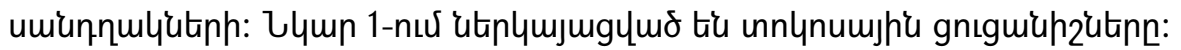

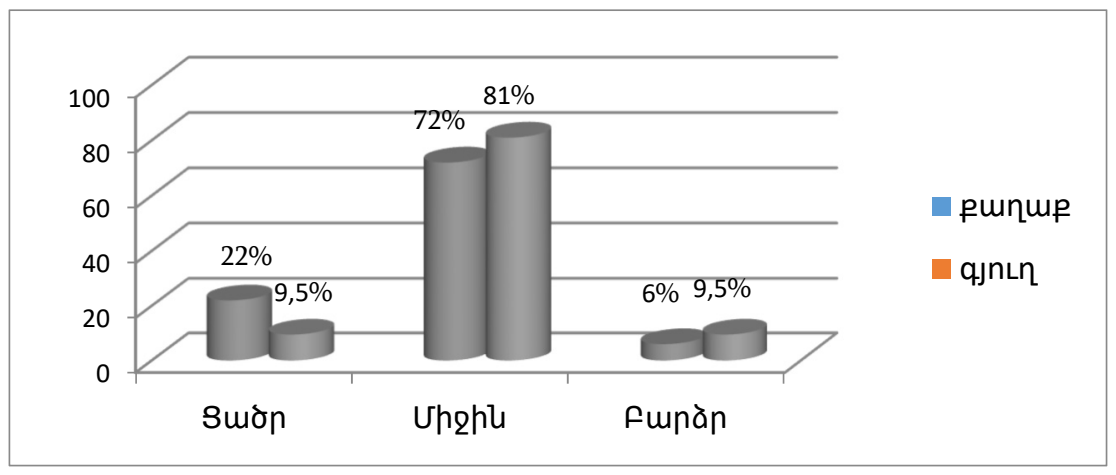

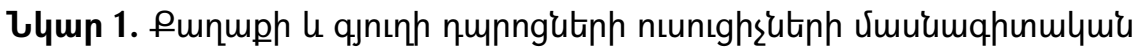
ujnưuiu gnıguiuhzutinn

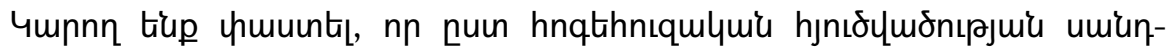

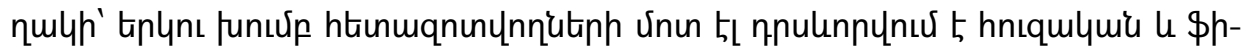

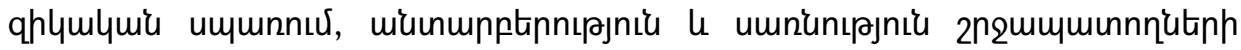

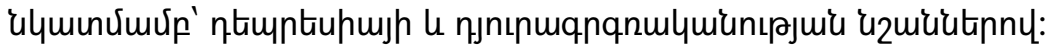

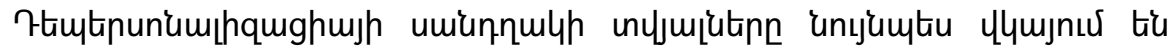

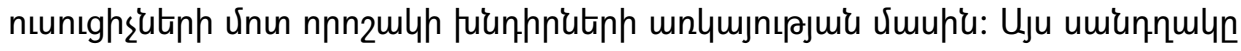

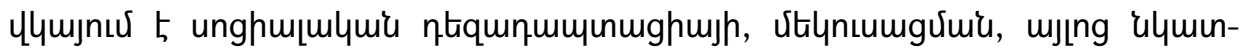

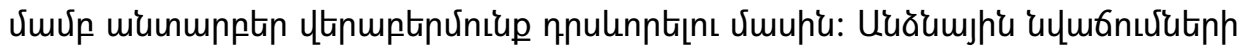

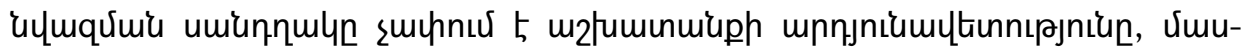

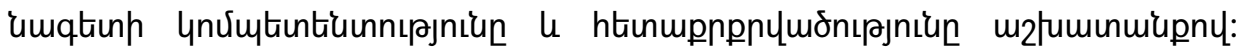

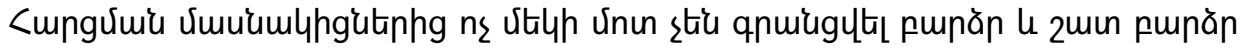

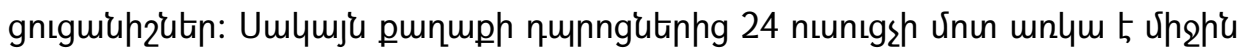




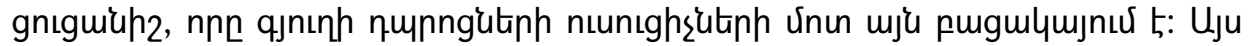

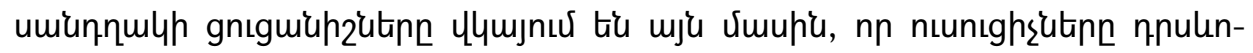

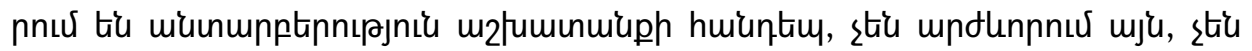

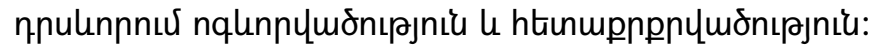

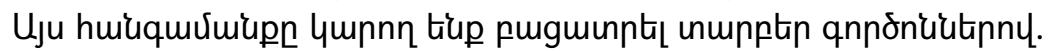

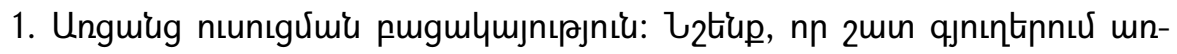

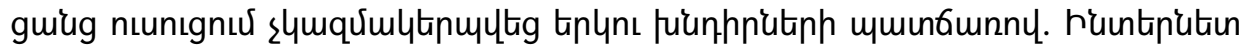

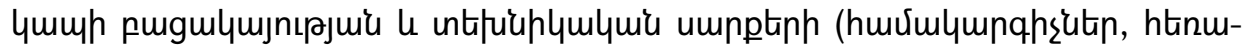

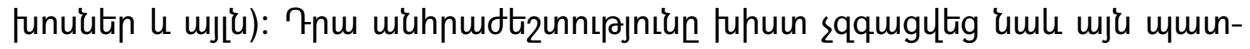

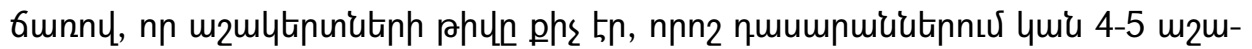

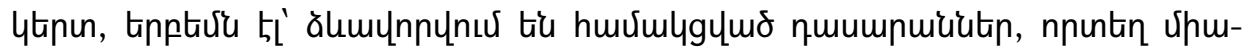

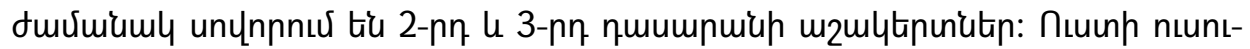

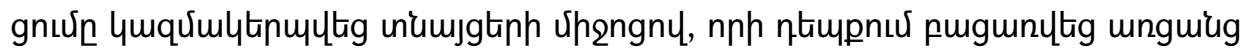

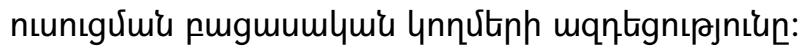

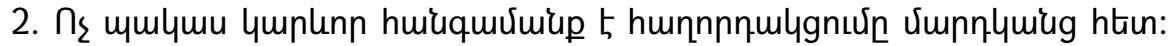

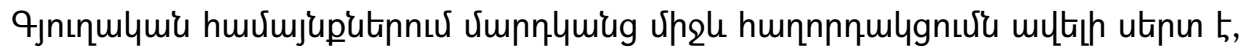

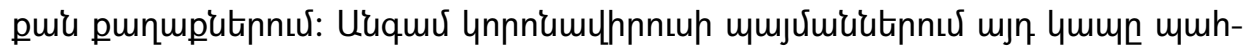

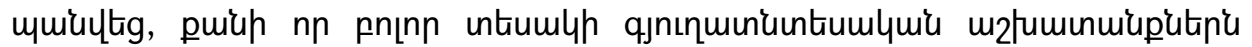

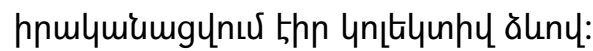

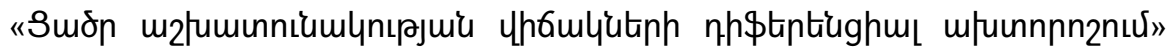

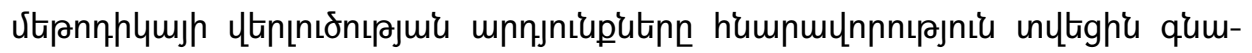

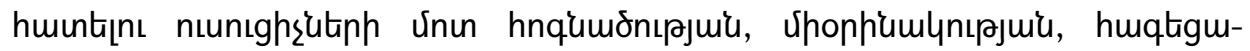

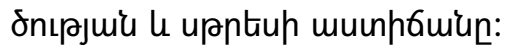

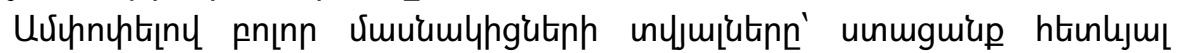
muinllinn.

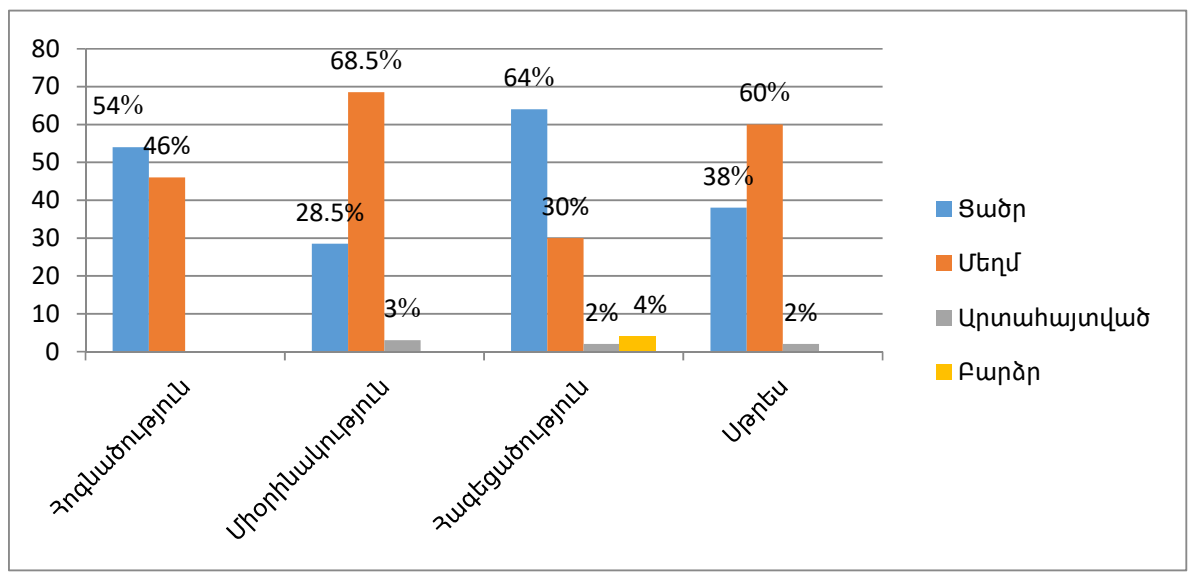

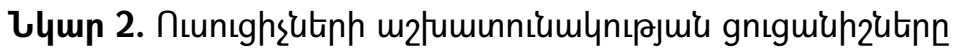




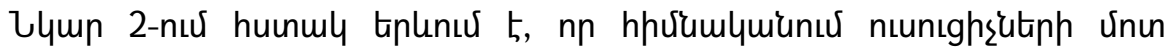

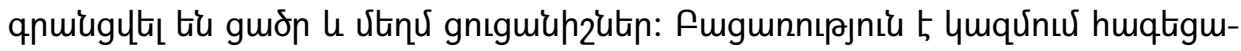

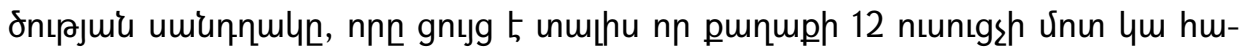

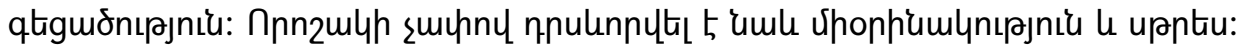

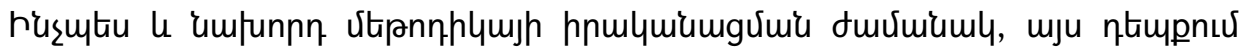

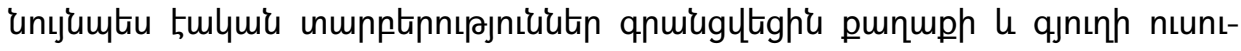
ghšlutph uholu:

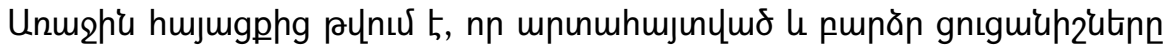

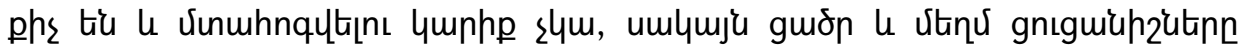

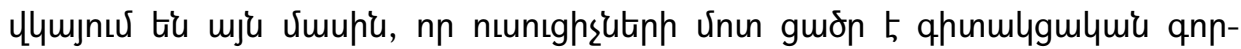

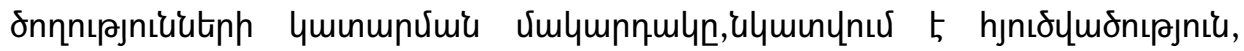
ămuănnıرp:

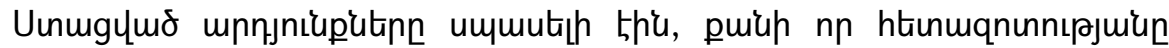

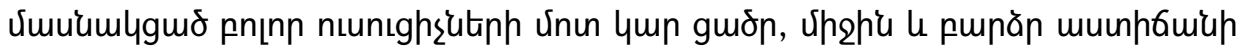
vimu'umqhunulquiu mjnnuर:

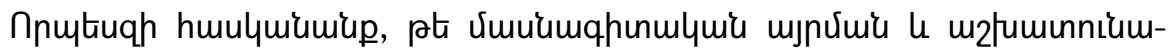

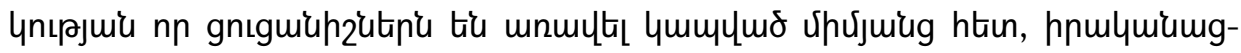

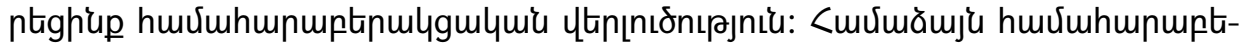

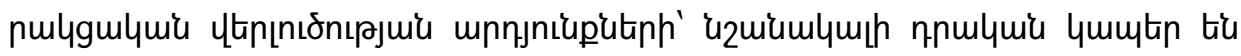

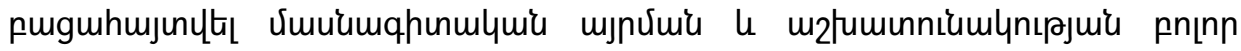

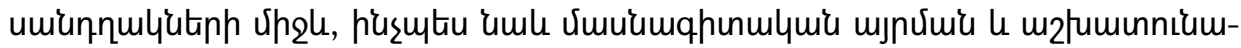

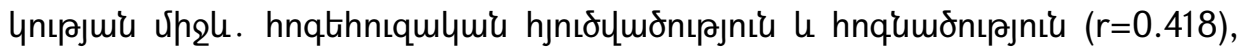

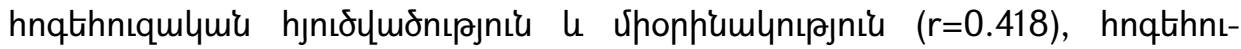

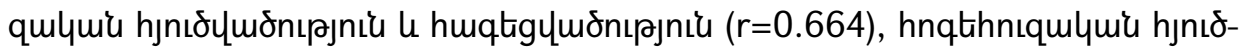

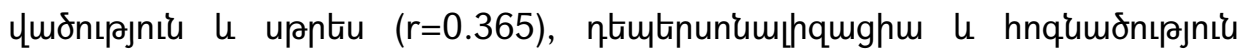

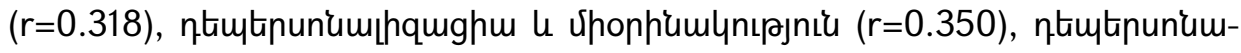

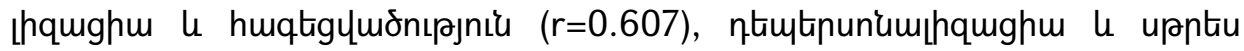

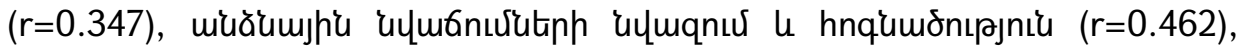

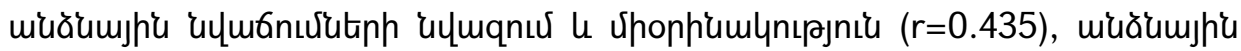

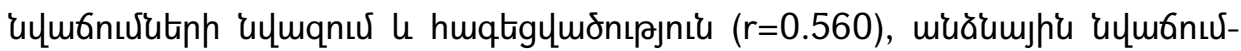

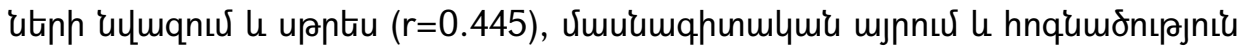

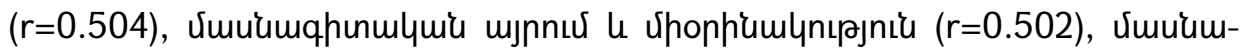

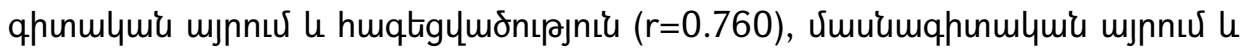

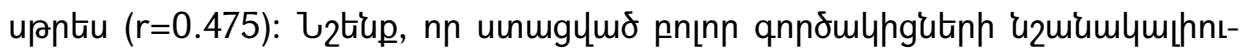
pjuiu Uulympnuly' $\mathrm{P} \leq 0.01$ :

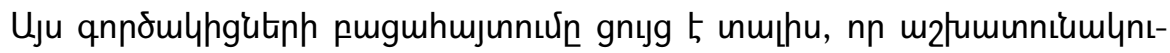

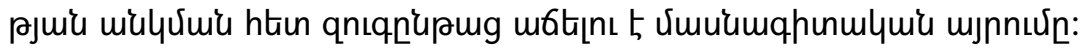

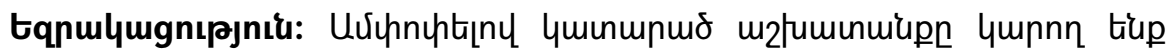
tqumlymgüt, $n$. 


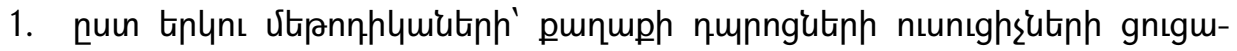

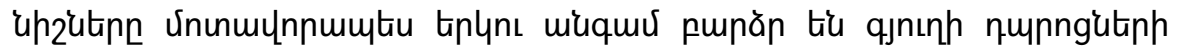

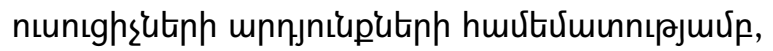

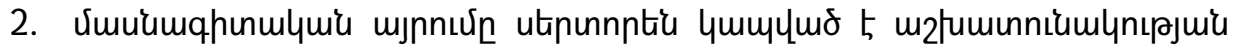
htien,

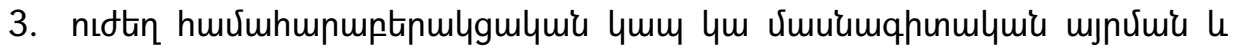
huqqugmonıpjuiu ungl:

\section{9pulquínıpjní}

1. Дорогина О.И. Работоспособность личности:Д69 психологические аспекты: практико-ориентированная монография [Текст] /О.И. Дорогина, Екатеринбург: Урал. гос. пед. ун-т, 2010. - 188 с., с. 4.

2. Лукина А.К. Психология труда. Методические рекомендации. Красноярск, 2004, 27 с., с. 31.

3. Медведев В. И.Терминология инженерной психологии [Текст] : Справочник/ В.И. Медведев, А.М. Парачев ; Воен.-мед. Краснознам. акад. им. С. М. Кирова. - Ленинград: [б. и.], 1971. - 111 с., с. 41.

4. Маслач К., Джексон С., В адаптации Н.Е. Водопьяновой/ Фетискин Н.П., Козлов В. В., Мануйлов Г.М. Диагностика профессионального выгорания Социально-психологическая диагностика развития личности и малых групп, М., 2002. с.360-362.

5. Леонова А., Величковская С. Дифференциальная диагностика состояний сниженной работоспособности (ДОРС).

http://deprimo.ru/psixodiagnostika-stressa/differencialnaya-diagnostikasostoyanij-snizhennoj-rabotosposobnosti-dors/.

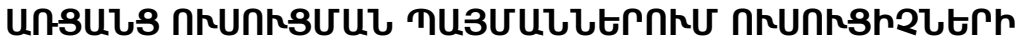

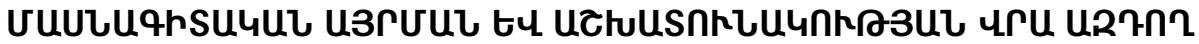 9กrбกuটtre}

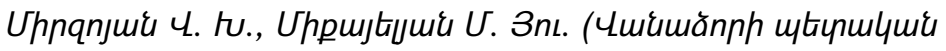

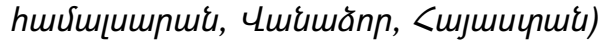

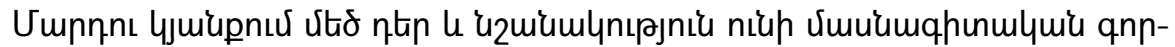

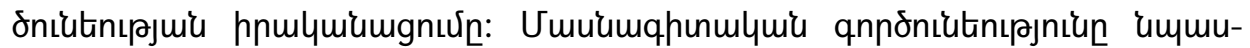

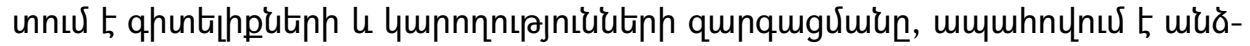

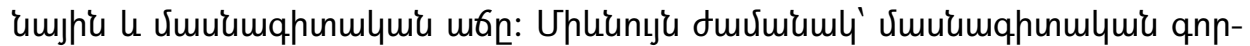

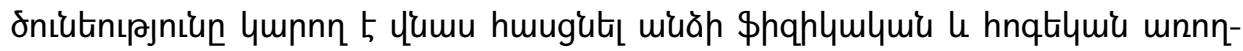

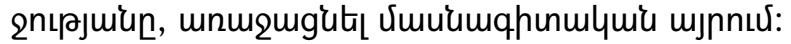

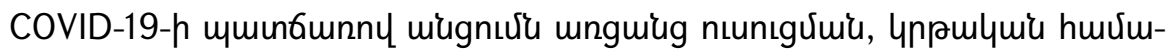

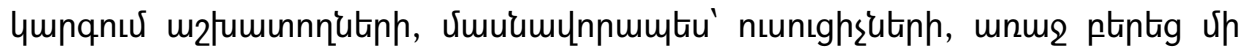




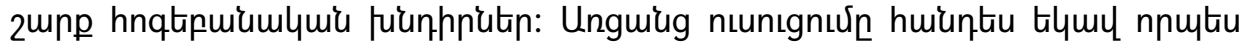

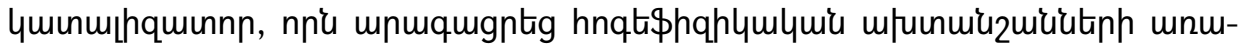

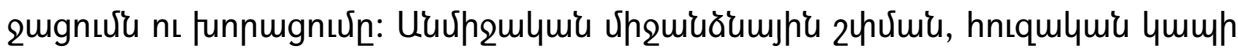

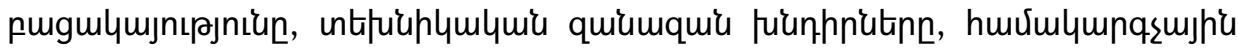

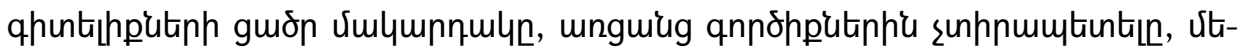

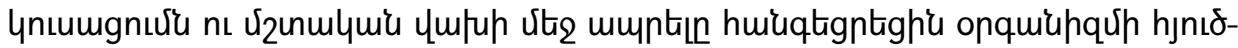

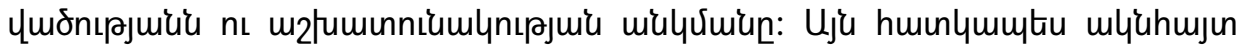

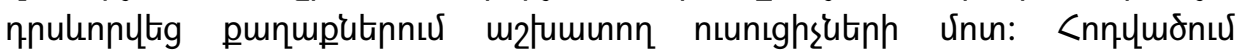

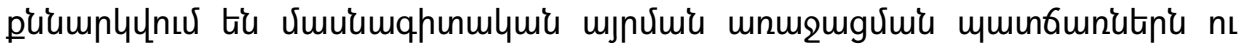

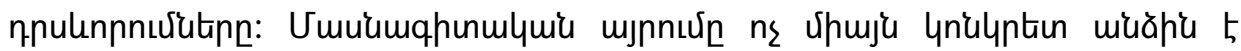

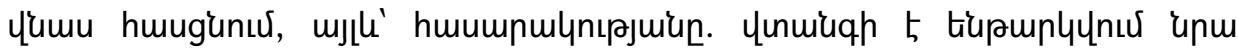

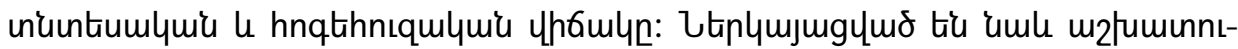

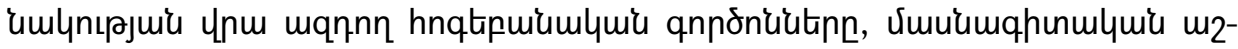

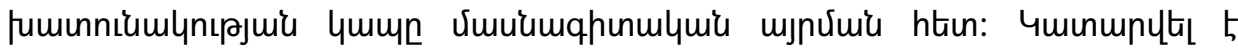

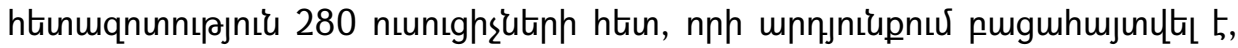

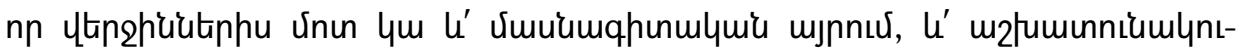

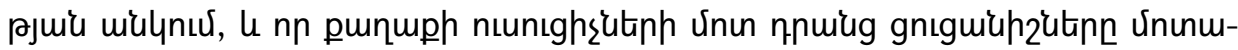
unnmultu tinlns míquư punăp tiú:

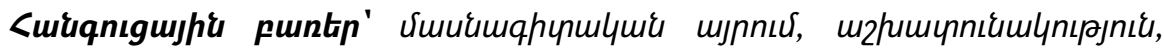

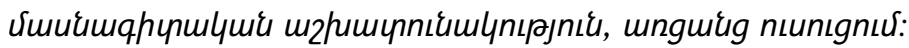

\title{
ФАКТОРЫ ПРОЯВЛЕНИЯ ПРОФЕССИОНАЛЬНОГО ВЫГОРАНИЯ И РАБОТОСПОСОБНОСТИ УЧИТЕЛЕЙ В УСЛОВИЯХ ОНЛАЙН ОБУЧЕНИЯ
}

\author{
Мирзоян В.Х., Микаелян М. Ю. (Ванадзоркий государственный \\ университет, Ванадзор, Армения)
}

Профессиональная деятельность имеет большую роль и значение в жизни человека. Она способствует обогащению знаний, развитию навыков, обеспечивает личностно-профрессиональный рост. В то же время профрессиональная деятельность может нанести вред физическому и психическому здоровью человека, вызвать профессиональное выгорание. Переходана онлайн - обучение в связи с COVID-19, у работников в системе образования, в частности у учителей, вызвал ряд психологических проблем. Онлайн - обучение стало катализатором, который ускорил возникновение и прогрессирование психофизических симптомов. Отсутствие непосредственного межличностного общения, эмоциональной связи, наличие различных технических проблем, низкий уровень компьютерной грамотности, неумение владеть онлайн инструментами, изоляция и постоянный страх привели к истощению организма и к снижению работоспособности. Особенно это было заметно среди учите- 
лей, работающих в городских школах. В статье обсуждаются причины возникновения профессионального выгорания и их проявления. Профессиональное выгорание вредит не только конкретному человеку, но и обществу в целом. Представлены психологические фракторы, влияющие на работоспособность, а также взаимосвязь между профессиональной работоспособностью и профессиональным выгоранием. Было проведено исследование с 280 учителями из городских и сельских школ, в результате которого констатировано снижение работоспособности и наличие профессионального выгорания, а также было выявлено, что показатели по двум методикам у учителей городских школ почти вдвое выше.

Ключевые слова: профессиональное выгорание, работоспособность, профессиональная работоспособность, онлайн-обучение. 